\title{
Enhanced Virgin Coconut Oil (EVCO) as Natural Postmilking Teat Germicide to Control Environmental Mastitis Pathogens
}

\author{
Koh Soo-Peng ${ }^{1}$, Dahlia Harun ${ }^{2}$, Maswati Mat-Amin ${ }^{2}$ and Kamariah Long ${ }^{1, *}$ \\ ${ }^{1}$ Biotechnology \& Nanotechnology Research Centre, Malaysian Agricultural Research \& Development \\ Institute (MARDI) PO Box 12301, 50774 Kuala Lumpur, Malaysia \\ ${ }^{2}$ Bacteriology Section, Veterinary Research Institute (VRI), 59, Jalan Sultan Azlan Shah, 31400 Ipoh, Perak, \\ Malaysia
}

\begin{abstract}
The antimicrobial capability of oil containing medium-chain fatty acids and their corresponding monoglycerides, known as Enhanced Virgin Coconut Oil (EVCO) against microorganisms isolated from bovine mastitis milk was studied. EVCO contains an effective amount of medium-chain free fatty acids (caprylic, capric and lauric acid) and their corresponding derivatives (monocaprylin, monocaprin and monolaurin) can act as antimicrobial agent with broad spectrum of antimicrobial properties. An in vitro assessment of EVCO against bovine mastitis microorganisms isolated from locally collected mastitis milk samples was conducted to determine its minimum bactericidal concentration $\left(\mathrm{MBC}_{>99}\right)$. In general, EVCO exhibited its great antimicrobial capability to kill all mastitis microorganisms isolated from the mastitis milk sample at different concentrations of $\mathrm{MBC}_{>99}$ value. In fact, EVCO was found more effective to kill Mycoplasma sp. and gram positive microbes rather than gram negative microbes, especially in Mycoplasma bovis, Acholeplasma oculi, Enterococcus sp., Streptococcus sp. and Staphylococcus aureus with lower $\mathrm{MBC}_{>99} \mathrm{Values}_{\text {in }}$ comparison with the synthetic antibiotic, Mastivet. A further investigation of the antimicrobial activities of EVCO against Staphylococcus aureus and Mycoplasma bovis against time revealed that EVCO was more efficient in killing these two microorganisms in a shorter time at a lower concentration as opposed to Mastivet. These findings indicated that EVCO has great potential application in postmilking teat germicide, which can be used as a preventive measure to control mastitis cases, especially against environmental mastitis pathogens.
\end{abstract}

Keywords: Mastitis, Enhanced Virgin Coconut Oil (EVCO), Mastivet, Antimicrobial Activity.

\section{INTRODUCTION}

Bovine mastitis is recognized as one of the most costly disease affecting dairy producer worldwide [1-3]. This pathology is caused by microbial intra-mammary infection that induces inflammation of the mammary glands. Mastitis disease has caused great economic loss that is associated with low yield in milk production and affected milk quality $[4,5]$. Staphylococcus aureus, Streptococcus agalactiae, Streptococcus dysagalactiae, Mycoplasma bovis and Streptococus uberis are some pathogenic microorganisms that are known to be responsible for clinical or subclinical mastitis infection in dairy industry [6-9]. Spread disease between dairy herds is influenced by management practices, particularly in milking procedure [10]. Staphylococcus aureus bovine mastitis is a major challenge to dairy producers. It can provoke clinical mastitis but most frequently, they are causing subclinical infection that tends to become chronic and difficult to eradicate using conventional antimicrobial therapies [11, 12]. Mycoplasma bovis is another important causal agent of clinical mastitis reported in the United States, Australia and Europe [8, 13, 14]. Mycoplasma bovis normally produces severe clinical

*Address correspondence to this author at the Biotechnology \& Nanotechnology Research Centre, Malaysian Agricultural Research \& Development Institute (MARDI), PO Box 12301, 50774 Kuala Lumpur, Malaysia; Tel: 03-89537238; Fax: 03-89536154; E-mail: amai@mardi.gov.my mastitis with a dramatic decline in milk production [4]. Treatment of clinical mastitis limits the duration and possible spread of the disease. Over the years, various antibiotics have been applied to control the mastitis disease. However, with the increasing public concern over food safety, there is high demand to minimize the use of therapeutic drugs in dairy herbs and avoid the incidence of drug residues in milk.

The antifungal and bactericidal properties of short and medium-chain fatty acids $\left(\mathrm{C}_{6}\right.$ to $\left.\mathrm{C}_{14}\right)$ and their derivatives (such as monoester) have widely known for some time [15]. In fact, the use of medium-chain fatty acids and its corresponding monoester as antimicrobial agent has been patented in food, cosmetic and pharmaceutical applications [16-18]. Monolaurin, monoester of laurin acid, is well known microbicide that capable to kill a wide range of bacteria, fungi, molds, mildew and viruses. This product has been marketed under the trademark Lauricidin [19]. In addition, Dee and co-researcher [16] have disclosed a novel antimicrobial composition consisting of the mixture of $\mathrm{C}_{8}$ to $\mathrm{C}_{14}$ fatty acids to kill harmful microbes on the udder of a milk producing animal.

Unlike others antimicrobial agent, Enhanced Virgin Coconut Oil (EVCO) is a modified virgin coconut oil that produced via enzymatic hydrolysis process [18]. EVCO is containing an effective amount of medium-chain free 
fatty acids (14.13\%; caprylic, capric and lauric acid) and their corresponding monoester (1.51\%; monocaprylin, monocaprin and monolaurin) which can act as an antimicrobial agent [18]. The uniqueness of EVCO is this product can be easily incorporated into either the aqueous phase or the oil phase due to its lipids class profile. It has pharmaceutical values and advantages over many of the synthetic antibacterial and antifungal creams in the market. Previous work by Long has claimed that EVCO has a broad spectrum of antimicrobial activities against pathogenic microorganisms including gram positive bacteria, i.e. Staphylococcus aureus, Listeria monocytogenes, Streptococcus pyogene; gram negative bacteria, i.e. Escherichia coli, Vibrio cholera and yeast, i.e. Candida albicans, C. krusei and Pityrosporumovale [18]. A preliminary study of anticoccidial activity of EVCO on broiler chicken coccidiosis showed a promising result with a significant reduction of oocysts level observed in faecal and cecal dramatically after 4 days posttreatment with EVCO [20], which has generally recognized as safe (GRAS) status and it can be a good and safer alternative way to control harmful pathogens. Prevention of new infection is a key strategy for mastitis control and milk quality management handling. Because of that, EVCO can be recommended as a preventive measure to reduce the mastitis cases in dairy industry. The present study attempted to examine the efficacy of EVCO to inhibit the growth of locally isolated mastitis microorganisms. A total of seven mastitis milk samples from local dairy farms were collected for the in vitro assessment. Mastivet, a strong antibiotic was chosen as reference antibiotic to compare the effectiveness of EVCO in the controlling of mastitis pathogens.

\section{MATERIALS AND METHODS}

\section{Materials}

A total of seven bovine mastitis milk samples (4 subclinical and 3 clinical cases) were used and labelled as 0152, 0137, 1381, 3272, 1728, 0172 and 1322. These mastitis milk samples were collected from our local dairy farms which were located in Selangor and Pahang state of Peninsular Malaysia. The Draminski mastitis detector was used to identify the subclinical and clinical milk sample.

\section{Preparation of Enhanced Virgin Coconut Oil (EVCO) from Virgin Coconut Oil}

The preparation of EVCO was conducted via enzymatic reaction according to Long's procedure [18].
A total of $2.5 \mathrm{~g}$ of 1,3 positional specific lipase was added into the volumetric flask containing mixture of $250 \mathrm{~g}$ virgin coconut oil and $2.5 \mathrm{~mL}$ distilled water. The mixed solution was stirring at the agitation rate of 160 $\mathrm{rpm}, 45^{\circ} \mathrm{C}$ for $24 \mathrm{~h}$. After that, samples were passed through funnel that containing sodium sulphate anhydrous powder to remove water and then centrifuged to separate oil phase. The lipid class and fatty acids composition of oil fraction were determined by high performance thin layer chromatography (HPTLC) and gas chromatography technique [18].

\section{Bacteria Isolation and Identification}

All the milk samples were cultured onto Blood agar and MacConkey agar for isolation of gram negative and gram positive bacteria, respectively. The plates were incubated at $37^{\circ} \mathrm{C}$ between 18 and $24 \mathrm{~h}$. The bacteria were subcultured few times to obtain a pure colony. The bacteria isolates were further identified and characterized by gram stain and conventional biochemical tests including indole test, methyl red test, Voges-Prokauer test, citrate test and sugar fermentation test [21].

\section{Mycoplasma Isolation and Identification}

Milk samples were cultured onto Pleuropneumonialike organism (PPLO) agar and PPLO broth. Then, agar plates were incubated at $37^{\circ} \mathrm{C}$ with $5 \%$ carbon dioxide while PPLO broth was incubated at $37^{\circ} \mathrm{C}$ under aerobic condition. The agar plate was examined for any Mycoplasma species which appears like "fried egg" colony every three to five days. Visible single colony was subcultured at least three times. PPLO broth was examined for $\mathrm{pH}$ change, within three to five days. Presumptive Mycoplasma colonies were subjected to biochemical tests for species identification. Growth inhibition test using reference strain antisera were carried out for species confirmation [22].

\section{Determination of Minimum Bactericidal Concentration $\left(\mathrm{MBC}_{>99}\right)$}

\section{Initial Count for Microbe}

All microorganisms isolated from bovine mastitis milk samples were cultured onto blood agar and incubated overnight. Five colonies were picked from the blood agar plates and inoculated into blood heart infusion (BHI) broth. Total bacteria count was conducted after $4 \mathrm{~h}$ incubation. The counts were read and recorded. Mycoplasma sp. isolates were cultured into PPLO broth and incubated for $20 \mathrm{~h}$ with the 
agitation rate set at $160 \mathrm{rpm}$. Total plate count was conducted using drop method.

\section{Minimum Bactericidal Concentration $\left(\mathrm{MBC}_{>99}\right)$ Of EVCO and Mastivet}

MBC for each microbe was determined using broth microdilution technique according to Koh and Long's method [23]. The isolate was cultured onto $\mathrm{BHI}$ broth and incubated for $4 \mathrm{~h}$ to obtain the initial bacteria count of $10^{7}-10^{8} \mathrm{cfu} / \mathrm{ml}$. A total of $120 \mu \mathrm{L} \mathrm{BHI}$ broth with $0.1 \%$ Tween 80 was added into each well. Fifty percent and five percent of EVCO were used as an initial working concentration to determine MBC for gram negative and gram positive microorganism, respectively. A respective amount of EVCO was added into first well and was mixed thoroughly by pipetting up and down about 30 times. Then, $120 \mu \mathrm{L}$ of mixture solution from the first well were transferred into second well and the same procedure was repeated until nine consecutive well using a multichannel pipette. Each well was containing $120 \mu \mathrm{L}$ of the test material in serially descending concentrations. Well 11 was a growth control and well 12 was a sterility control. Finally, $20 \mu \mathrm{L}$ of inoculums containing bacterial suspension $\left(10^{7}-10^{8} \mathrm{cfu} / \mathrm{mL}\right)$ were added into each well from well 1 to 11. After that, the plate was rotated using microtiter plate shaker (TiterTac) for $15 \mathrm{~min}$. The plate was rotated for another two times before it was incubated using incubator shaker at $160 \mathrm{rpm}$ overnight.

Prior to perform the plate count, the plate was rotated for five min. Plate counts for each dilution were performed in triplicates for more precise reading. Serial dilutions were performed in Eppendorf tube using micropipettes. All plates were incubated at $37^{\circ} \mathrm{C}$ between 18 and 24 h. After incubation, the colonies from each plate were counted and recorded. In this study, it was noted that both E. coli and Pseudomonas were found not susceptible to EVCO at the concentration of $50 \%$. Therefore, the concentration of EVCO has been increased in order to determine the MBC for both organisms. Single mixing method for each well has been used to get the desired ratio between inoculums and product tested as titration method was found not suitable for concentration of EVCO higher than $50 \%$. In comparison to the EVCO efficacy study, Mastivet has been chosen as reference mastitis antibiotic. This antibiotic has been tested parallel with EVCO using the same broth micro dilution method. Minimal bactericidal concentration, $\mathrm{MBC}_{>99}$ was defined as the lowest concentration of EVCO or
Mastivet that will inhibit $>99 \%$ of the visible growth of a microorganism after overnight incubation.

\section{Bactericidal Activity of EVCO on Staphylococcus Aureus and Mycoplasma Bovis}

The bactericidal activity study was conducted to determine the microbial reduction of Staphylococcus aureus and Mycoplasma bovis colonies at specified exposure time after EVCO and Mastivet treatment. In this study, one colony of Staphylococcus aureus from overnight culture was cultured into $\mathrm{BHI}$ broth and was incubated at $37^{\circ} \mathrm{C}$ with agitation rate set at $130 \mathrm{rpm}$ for $24 \mathrm{~h}$. Then, the inoculums suspension of $10^{8} \mathrm{cfu} / \mathrm{mL}$ was added to the $\mathrm{BHI}$ broth that containing $0.1 \%$ Tween 80 at a ratio of $1: 10$. This broth was mixed with either the EVCO or Mastivet at $0.63 \%$ and $1.25 \%$, respectively. Samplings were carried out six times at 0 , $0.17,0.5,1,6$ and $24 \mathrm{~h}$ with a total of $100 \mu \mathrm{L}$ of broth suspension was removed for total plate count analysis. A serial dilution was performed in sterile normal saline. Total plate count was carried out on nutrient agar using spread plate method to obtain the viable bacteria count. All the plates were incubated at $37^{\circ} \mathrm{C}$ between 16 and $24 \mathrm{~h}$.

For Mycoplasma bovis case, ten colonies of Mycoplasma bovis were cultured into PPLO broth and incubated at $37^{\circ} \mathrm{C}$ for $48 \mathrm{~h}$ with the incubator shaker set at $140 \mathrm{rpm}$. The culture was then subjected to time kill study. The inoculums suspension of $10^{9} \mathrm{cfu} / \mathrm{mL}$ was added into the PPLO broth that containing $0.1 \%$ Tween 80 at a ratio of $1: 10$ and were mixed with either the EVCO or Mastivet at $0.08 \%$ and $1.25 \%$, respectively. The same samplings time were conducted as described above. Total plate count of Mycoplasma bovis was performed on PPLO agar using drop method. All the plates were incubated at $37^{\circ} \mathrm{C}$ for $48 \mathrm{~h}$.

\section{RESULTS}

A number of microorganisms have been identified from the seven mastitis milk samples collected from two different locations of dairy farm in Malaysia. In general, all identified microbes from bovine mastitis milks were found to be the same group of microorganisms that were known to be responsible for the subclinical and clinical mastitis cases in dairy industry. It was noted that bacterial species was the mostly found isolates, which was six out of seven samples. These bacterial species consisting of gram positive and gram negative microbes as summarized in Table 1. The gram positive microbes include Enterococcus mundtii, Enterococcus avium, a-haem 
Table 1: Types of Microorganism Isolated from Seven Bovine Mastitis Milk Samples Collected from Locally Dairy Farm of Malaysia

\begin{tabular}{|c|c|c|c|c|}
\hline Sample & Code & Bacteria & Mycoplasma & Total isolates \\
\hline \multirow[t]{4}{*}{ Subclinical } & 0152 & $\begin{array}{c}\text { Enterobacter } s p . \\
\text { Enterococcus mundtii }\end{array}$ & $\begin{array}{l}- \\
-\end{array}$ & 2 \\
\hline & 0137 & $\begin{array}{c}\text { Escherichia coli } \\
\text { Enterococcus avium } \\
\alpha \text {-haem Streptococcus sp. } \\
\text { (Lancefield Group B) }\end{array}$ & Mycoplasma bovis & 4 \\
\hline & 1381 & $\begin{array}{c}\text { Escherichia coli } \\
\text { Yeast }\end{array}$ & Acholeplasma oculi & 3 \\
\hline & 3272 & Yeast & Acholeplasma oculi & 2 \\
\hline \multirow[t]{3}{*}{ Clinical } & 1728 & $\begin{array}{c}\text { Escherichia coli } \\
\alpha \text {-haem Streptococcus sp. } \\
\text { (Lancefield Group B) }\end{array}$ & Acholeplasma oculi & 3 \\
\hline & 0172 & $\begin{array}{l}\text { Enterococcus mundtii } \\
\text { Pseudomonas } s p .\end{array}$ & - & 2 \\
\hline & 1322 & $\begin{array}{c}\text { Staphylococcus aureus } \\
\text { Escherichia coli } \\
\text { Corynebacterium sp. }\end{array}$ & - & 3 \\
\hline
\end{tabular}

Streptococcus sp. (Lancefield Group B), Staphylococcus aureus and Corynebacterium. Enterobacter sp., Escherichia coli and Pseudomonas $s p$. were among gram negative microbes isolated from mastitis milk samples. Two types of Mycoplasma $s p$. also noted present in four out of seven milk samples, which were Mycoplasma bovis and Acholeplasma oculi. The presence of yeast was also detected in some of the subclinical milk samples. Table 2 shows the minimum bactericidal concentration $\left(\mathrm{MBC}_{>99}\right)$ of EVCO and Mastivet against mastitis microorganisms isolated from mastitis milk samples with more than $99 \%$ killing rate. In general, EVCO and Mastivet had shown their different antimicrobial capability to eradicate all mastitis microorganisms identified from local mastitis milk samples at the different value of $\mathrm{MBC}_{>99}$. Overall,
EVCO revealed to have better antimicrobial activities against gram positive microbes and Mycoplasma $s p$. than gram negative microbes especially for Mycoplasma bovis, Acholeplasma oculi, Streptococcus $s p$. and Staphylococcus aureus with lower $\mathrm{MBC}_{>99}$ value in comparison to synthetic antibiotic, Mastivet. Overall, the results obtained indicating that EVCO has the antimicrobial capability to inhibit the growth of locally identified mastitis microorganisms even though it was less effective against gram negative microbes as opposed to Mastivet.

Based on data collected from the $\mathrm{MBC}_{>99}$ study on EVCO and Mastivet, a further investigation on the selected mastitis microorganisms against time was carried out. Two types of mastitis microorganism,

Table 2: Minimum Bactericidal Concentration $\left(\mathrm{MBC}_{>99}\right)$ of EVCO and Mastivet Against Mastitis Microorganisms Isolated from Local Bovine Mastitis Milk Samples

\begin{tabular}{|c|c|c|c|}
\hline \multirow{2}{*}{ Type of Microbe } & & \multicolumn{2}{|c|}{ Minimum bactericidal Concentration $\left(\mathrm{MBC}_{>99}\right)$} \\
\hline & & EVCO (\%) & Mastivet (\%) \\
\hline Bacteria & $\begin{array}{c}\text { Escherichia coli } \\
\text { Enterococcus mundtii } \\
\alpha \text {-haem Streptococcus sp. } \\
\text { (Lancefield Group B) } \\
\text { Corynebacterium sp. } \\
\text { Pseudomonas sp. } \\
\text { Staphylococcus aureus }\end{array}$ & $\begin{array}{l}50.0 \pm 0.00 \\
2.50 \pm 0.00 \\
0.63 \pm 0.00 \\
0.63 \pm 0.00 \\
65.0 \pm 0.00 \\
0.63 \pm 0.00\end{array}$ & $\begin{array}{c}1 \pm 0.00 \\
10 \pm 0.00 \\
20 \pm 0.00 \\
0.04 \pm 0.00 \\
1.25 \pm 0.00 \\
1.25 \pm 0.00\end{array}$ \\
\hline Mycoplasma & $\begin{array}{l}\text { Mycoplasma bovis } \\
\text { Acholeplasma oculi }\end{array}$ & $\begin{array}{l}0.08 \pm 0.00 \\
0.04 \pm 0.00\end{array}$ & $\begin{array}{l}1.25 \pm 0.00 \\
0.63 \pm 0.00\end{array}$ \\
\hline
\end{tabular}

The MBC is identified by determining the lowest concentration of EVCO that reduces the viability of the initial bacterial inoculum by $\geq 99.9 \%$. Each value in the Table represents the mean \pm standard deviation from triplicate analyses. 


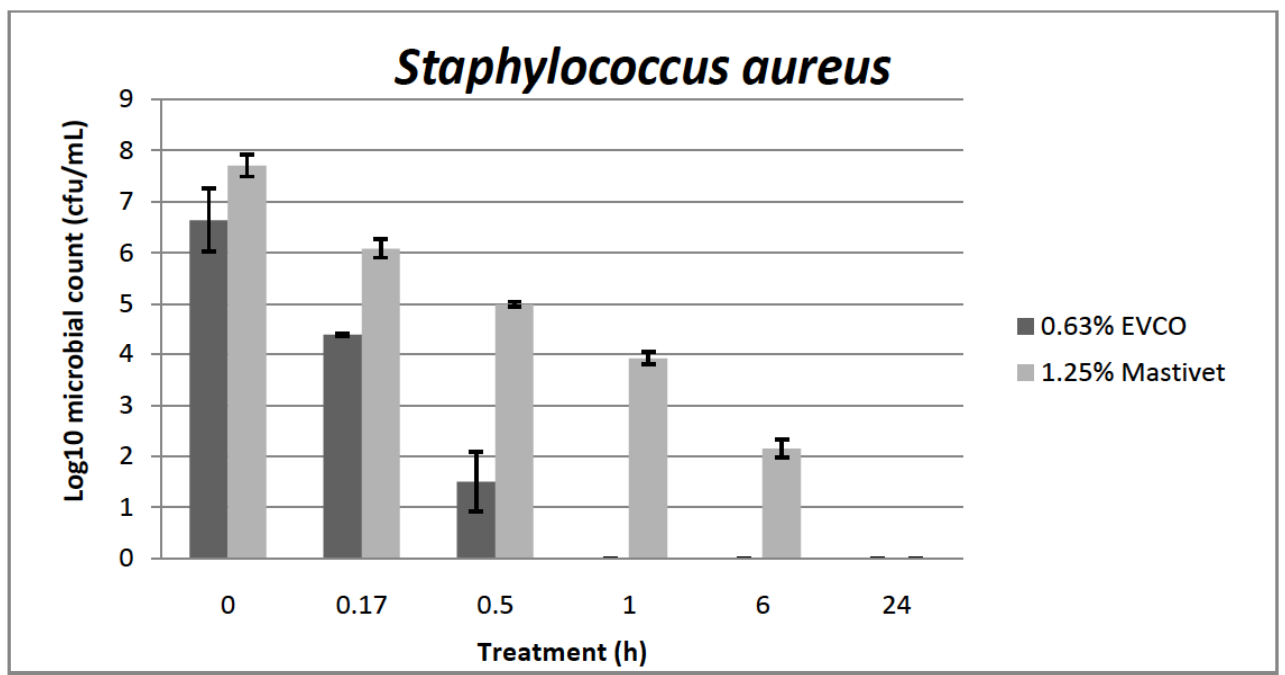

(a)

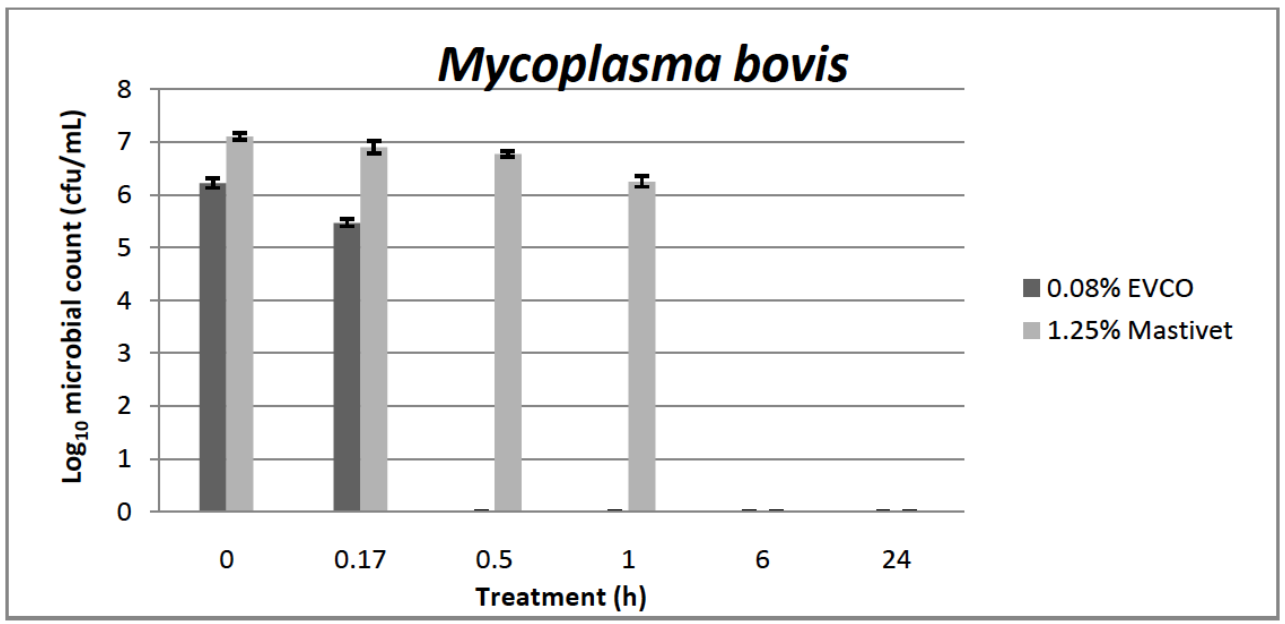

(b)

Figure 1: The effect of EVCO and Mastivet on $\log _{10}$ microbial reduction count (cfu/mL) versus exposure time: a) Staphylcoccus aureus; b) Mycoplasma bovis.

Each value in the Figure represents the mean \pm standard deviation from triplicate analyses.

namely as Staphylococcus aureus and Mycoplasma bovis were chosen to determine their microbial reduction at the specified exposure time under the defined concentration of EVCO and Mastivet. In comparison to synthetic antibiotic, Mastivet, EVCO appeared to be more efficient to kill both Staphylococcus aureus and Mycoplasma bovis at a shorter time with lower concentration used (Figure 1). Mycoplasma bovis was easily killed within 30 min with the use of $0.08 \%$ of EVCO. On the contrary, Staphylococcus aureus required an hour with higher percentage of EVCO $(0.63 \%)$ in order to be totally eradicated compared with Mycoplasma bovis. On the other hand, Mastivet with the concentration of $1.25 \%$ required longer time to kill both Staphylococcus aureus and Mycoplasma bovis as opposed to EVCO, which were $24 \mathrm{~h}$ and $6 \mathrm{~h}$, respectively.

\section{DISCUSSION}

As reported in previous findings, the major mastitis causal agent such as Enterococcus sp., Staphylococcus aureus, Escherichia coli, $\alpha$-haem Streptococcus sp.and Mycoplasma bovis were those microorganisms isolated from the mastitis milks found in local dairy farm also [7, 8, 10]. Some yeast was detected in the subclinical samples and was reported to play primary or secondary roles in causing mycotic mastitis [24, 25]. Based on frequency of isolation, Escherichia coli (4X), Enterococcus sp. (3X) and Acholeplasma oculi (3X) were the most common microbes found in the mastitis milk samples, followed by $\alpha$-haem Streptococcus sp. (2X), yeast (2X), Mycoplasma bovis (1X), Enterobacter sp. (1X), Corynebacterium (1X), Staphylococcus aureus (1X) 
and Pseudomonas $s p$. (1X). All the mastitis microorganism isolates were the same group of microorganisms reported from previous mastitis case before and usually regarded as the agent for environmental mastitis except for Mycoplasma bovis which is known as causal agent for contagious mastitis $[13,26]$.

From the minimum bactericidal concentration assay, EVCO was shown to have different antimicrobial capability to cause growth inhibition in all mastitis microorganisms isolated from bovine mastitis milks. In particular, EVCO was found more effectively to kill the gram positive than gram negative microbes. Enterococcus mundtii, a-haem Streptococcus sp., Corynebacterium and Staphylococcus aureus were those gram positive microbes that showed low $\mathrm{MBC}_{>99}$ value of EVCO. In fact, $\mathrm{MBC}_{>99}$ value of EVCO against Enterococcus mundtii, a-haem Streptococcus sp. and Staphylococcus aureus was found lower than Mastivet. Furthermore, treatment with EVCO showed the highest antimicrobial activity against Mycoplasma bovis and Acholeplasma oculi with the $\mathrm{MBC}_{>99}$ value of EVCO below $0.1 \%$, which was lower than Mastivet. This is an important finding as those microbes are known hardly to be eradicated and cause a dramatic decline in milk $[4,6]$. Unlike Mastivet, EVCO has GRAS status [18] and is not harmful to human or animals. Therefore, EVCO can be a good alternative treatment to replace current therapeutic drugs, which may be remained as a residue in milk with regards on the food safety issue.

In comparison to Mastivet, EVCO was noted less effective against gram negative microbes like Escherichia coli and Pseudomonas $s p$. with the $\mathrm{MBC}_{>99}$ value above $50 \%$. Most probably, the less efficacy of EVCO against gram negative microbes was due to the differences in the microbial cell wall, whereby the gram negative microbes contain a thick layer of peptidoglycans in their cell wall. In addition, the Pseudomonas sp. has shown to be able to adapt selective pressure to various class of antimicrobial agent and was very fast to develop resistance and persistence in its infection as reported by Anita and coresearchers (2007) [27]. Combination of few antibiotics in Mastivet was found able to kill the Pseudomonas at the $\mathrm{MBC}_{>99}$ value of $1 \%$. This phenomenon may be due to the quick response of antibiotic before the Pseudomonas sp. built up the drug resistance. In fact, Mastivet acts as beta-lactam antibiotic, whereby it inhibits the synthesis of the bacterial cell membrane. The curing response of EVCO may be slower than Mastivet, resulting less efficient against Pseudomonas $s p$. Nevertheless, EVCO still able to inhibit the growth of Pseudomonas sp. and it is much safer compared to Mastivet although the dosage used was above $50 \%$.

Based on the killing rate in the $\mathrm{MBC}_{>99}$ study, Staphylococcus aureus and Mycoplasma bovis have been selected to examine the efficacy of EVCO against exposure time. Overall, the results obtained showed that EVCO is more efficient to kill Staphylococcus aureus and Mycoplasma bovis at a shorter time with lower concentration $(0.63 \%$ and $0.08 \%$, respectively) as opposed to Mastivet (1.25\%). The good curing response of EVCO against these two microorganisms may be due to the type of cell membrane structure exists in the Staphylococcus aureus and Mycoplasma bovis, whereby EVCO can be easily penetrated into the cell wall, subsequently, resulting the growth inhibition. In fact, both Staphyloccus aureus and Mycoplasma bovis was easily eradicated within an hour, showing that EVCO more effective than Mastivet. In summary, both in-vitro assessments on the efficacy study of EVCO against mastitis microorganisms isolated from locally mastitis milk samples have shown its better antimicrobial activities than Mastivet. The finding obtained indicating that EVCO have good potential to be employed in the mastitis preventive measures, especially against environmental mastitis pathogens.

\section{CONCLUSION}

The presence of significant amount of mediumchain free fatty acids and their corresponding monoesters of EVCO had particularly shown its antimicrobial action against gram positive microbes and Mycoplasma species better than synthetic antibiotic (Mastivet). This finding has demonstrated that EVCO has high potential as anti-infective in the management of milk quality control against mastitis threats. In fact, EVCO can serve as an effective teat dip germicides to eradicate any possible mastitis infection from surrounding area, particularly for dairy industry to minimise the economic loss related to mastitis cases.

\section{ACKNOWLEDGEMENT}

This study was financially supported by Ministry of Agricultural through Technofund grant (TF0106B139). We thank Veterinary Research Institute staffs for the technical assistance support throughout the study.

\section{REFERENCES}

[1] Costal EO, Melville PA, Ribeiro AR, Watanabe ET, Parolari MC. Epidemiologic study of environmental sources of a 
Protothecazopfii outbreak of bovine mastitis. Mycopathologia 1997; 137: 33-6.

http://dx.doi.org/10.1023/A:1006871213521

[2] Moretti A, Pasquali P, Mencaroni G, Boncio L, Fioretti D P. Relationship between cell counts in bovine milk and the presence of mastitis pathogens (yeast and bacteria). Zentralbl Veterinarmed [B] 1998; 45: 129-32. http://dx.doi.org/10.1111/j.1439-0450.1998.tb00775.x

[3] Bradley AJ, Green MJ. Aetiology of clinical mastitis in six Somerset dairy herds. Vet Rec 2001; 148: 683-6. http://dx.doi.org/10.1136/vr.148.22.683

[4] Jasper DE. Bovine mycoplasmal mastitis. Adv Vet Sci Comp Med 1981; 25: 121-6.

[5] Fang W, Shi M, Huang L, Shao Q, Chen J. Growth of Lactobacilli, Staphylococcus aureus and Escherichia coli in normal and mastitic milk and whey. Vet Microbiol 1993; 37: 115-25. http://dx.doi.org/10.1016/0378-1135(93)90186-B

[6] Leitner G, Lubashevsky E, Trainin Z. Staphylococcus aureus vaccine against mastitis in dairy cows, composition and evaluation of its immunogenicity in a mouse model. Vet. Immunol Immunopathol 2003; 93: 159-67. http://dx.doi.org/10.1016/S0165-2427(03)00069-2

[7] Gröhn YT, Wilson DJ, González RN, Hertl JA, Schulte H, Bennett G, Schukken YH. Effect of pathogen-specific clinical mastitis on milk yield in milk yield in dairy cows. J Dairy Sci 2004; 87: 3358-74. http://dx.doi.org/10.3168/jds.S0022-0302(04)73472-4

[8] Filioussis G, Christodoulopoulos G, Thatcher A, Petridou V, Bourtzi-Chatzopoulou E. Isolation of Mycoplasma bovis from bovine clinical mastitis cases in Northern Greece. Vet J 2007; 173: $215-8$ http://dx.doi.org/10.1016/j.tvjl.2005.08.001

[9] Fadlelmula A, AL Dughaym AM, Mohamed GE, AL Deib MK, Zubaidy AJ. Bovine mastitis: epidemiological, clinical and etiological study in a Saudi Arabian large dairy farm. Bulgarian J Vet Med 2009; 12: 199-206.

[10] Anderson N. Dairy Barns and Mastitis, in Infosheet from OMAFRA: Dairy Cow Comfort 2008; 1-8.

[11] Bramley AJ. The effect of sub-clinical Staphylococcus epidermidis infection of the lactating bovine udder on its susceptibility to infection with Streptococcus agalactiae or Escherichia coli. Br Vet J 1978; 34: 146-51.

[12] Brouillette E, Malouin F. The pathogenesis and control of Staphylococcus aureus-induced mastitis: study models in the mouse. Microb Infect 2005; 7: 560-8. http://dx.doi.org/10.1016/j.micinf.2004.11.008

[13] Ayling RD, Bashiruddin JB, Nicholas RA. Mycoplasma species and related organisms isolated from ruminants in Britain between 1990 and 2000. Vet Rec 2004; 155: 413-6. http://dx.doi.org/10.1136/vr.155.14.413
[14] Bryne W, Markey B, McCormack R, Egan J, Ball H, Sachse $\mathrm{K}$. Persistence of Mycoplasma bovis infection in the mammary glands of lactating cows inoculated experimentally. Vet $\operatorname{Rec} 2005 ; 156: 767-71$.

\section{http://dx.doi.org/10.1136/vr.156.24.767}

[15] Kabara JJ, Swieczkowski DM, Conley AJ, Truant JP. Fatty acids and derivatives as antimicrobial agents. Antimicrob Agents Chemother 1972; 2: 23-8. http://dx.doi.org/10.1128/AAC.2.1.23

[16] Dee A, Gradle C. Fatty acid antimicrobial. US patent 2004/0167221A1. 2004

[17] Richter FL, Reinhardt DJ. Antimicrobial compositions formulated for use in cold temperature conditions and method of use thereof. US patent 7109241 B1, 2006.

[18] Long K. Modified coconut oils with broad antimicrobial spectrum. Malaysian Granted Patent MY140578-A. 2009

[19] Hart ER. Cleaner leaving an antimicrobial film. US patent 2006/0030512 A1. 2006.

[20] Tan GH, Long K. Preliminary study of anticoccidial activity of medium chain fatty acids (MCFA) and their corresponding monoglycerides on broiler chicken coccidiosis. International Journal of Biotechnology for Wellness Industries 2012; 1: 134-41. http://dx.doi.org/10.6000/1927-3037/2012.01.02.05

[21] Quinn PJ, Carter ME, Markey BK, Carter GR. Clinical Veterinary Microbiology. London: Mosby-Year Europe Limited; 1994: pp 21-66 \& 327-344.

[22] Tan LJ. Diagnostic technique on mammalian Mycoplasma. In: Laboratory Working Manual. Malaysia: Veterinary Research Institute; 1986

[23] Koh SP, Long K. The antimicrobial activity of Enhanced Virgin Coconut Oil (EVCO) on growth of mastitis growth pathogens. Malaysian Journal of Microbiology. 2014; 10:1128.

[24] Farnsworth RJ, Sorensen DK. Prevalence and species distribution of yeast in mammary glands of dairy cows in Minnesota. Can J Comp Med 1972; 36: 329-32.

[25] Chahota R, Katoch R, Mahajan A, Subhash V. Clinical bovine mastitis caused by Geotrichum candidum. Veterinarski Arhiv 2001; 71: 197-201

[26] Blackmer PE. Mycoplasma bovis in large dairy herds: sharing 28 years of practice experience. In: Proceedings of $84^{\text {th }}$ Annual Conference. Wisconsin Veterinary Medical Association, Medison, PA, 1998: pp. 145.

[27] Anita R, Thilo K, Paul W, Peter R. Development and persistence of antimicrobial resistance in Pseudomonas aeruginosa: a longitudinal observation in mechanically ventilated patients. Antimicrob Agents Chemother 2007; 51: 1341-50. http://dx.doi.org/10.1128/AAC.01278-06

\section{DOI: http://dx.doi.org/10.6000/1927-3037.2016.05.04.2}

(C) 2016 Soo-Peng et al.; Licensee Lifescience Global.

This is an open access article licensed under the terms of the Creative Commons Attribution Non-Commercial License (http://creativecommons.org/licenses/by-nc/3.0/) which permits unrestricted, non-commercial use, distribution and reproduction in any medium, provided the work is properly cited. 